\title{
Surface Salinity Measurements-COSMOS 2005 Experiment in the Bay of Biscay
}

\author{
G. Reverdin, * P. Blouch, ${ }^{+}$J. Boutin,* P. P. Niller, ${ }^{\#}$ J. Rolland, ${ }^{+}$W. Scuba, ${ }^{\#}$ A. Lourenco, ${ }^{*}$ \\ AND A. F. RiOs@ \\ * LOCEAN/IPSL, CNRS/UPMC, Paris, France \\ $+C M M / C N R M$, Brest, France \\ \# Scripps Institution of Oceanography, La Jolla, California \\ @ CSIC, Instituto de Investigaciones Mariñas, Vigo, Spain
}

(Manuscript received 7 July 2006, in final form 24 January 2007)

\begin{abstract}
Sea surface salinity (SSS) data were collected in the Bay of Biscay between April and November 2005. The major source of data is 15 surface drifters deployed during the COSMOS experiment in early April and early May 2005 [12 from the Scripps Instution of Oceanography (SIO) and 3 from METOCEAN]. This is complemented by thermosalinograph (TSG) data from four French research vessels and four merchant vessels, from salinity profiles collected by Argo profiling floats and CTD casts, and from surface samples during two cruises. Time during the two cruises was dedicated to direct inspection of the drifters, recovering some, and providing validation data. This dataset provides a unique opportunity to estimate the accuracy of the SSS data and to evaluate the long-term performance of the drifter salinities. Some of the TSG SSS data were noisy, presumably from bubbles. The TSG data from the research vessels needed to be corrected from biases, which are very commonly larger than 0.1 pss-78 (practical salinity scale), and which in some instances evolved quickly from day to day. These corrections are only available when samples were collected or ancillary data are available (e.g., from CTD profiles). The resulting accuracy of the corrected TSG dataset, which varies strongly in time, is discussed. The surface drifter SSS data presented anomalous daytime values during days with strong surface warming. These data had to be excluded from the dataset. The drifter SSS presented initial biases in the range 0.009 to -0.026 pss- 78 . The (usually) negative bias increased by an average of -0.007 pss- 78 during the average 65-day period before the COSMOS- 2 cruise on 22-27 June. High chlorophyll derived from satellite ocean color, and therefore high density of phytoplanktonic cells, is observed in Medium Resolution Imaging Spectrometer (MERIS)/Moderate Resolution Imaging Spectroradiometer (MODIS) composites during part of the period, in particular in late April or early May. No correlation was found between the change in bias and the estimated surface chlorophyll. Evolution during the following summer months is harder to ascertain. For three buoys, there is little change in bias, but for two others, there could have been an increase in bias by up to 0.03 or 0.04 pss- 78 during July-August. Seven drifters were recovered in the autumn, which provide recovery or postrecovery estimates of the biases, suggesting in three cases (out of seven) a large (0.02-0.03 pss-78) increase in bias during the autumn months, but no significant increase for the other four drifters.
\end{abstract}

\section{Introduction}

Sea surface salinity (SSS) is a key climate variable [e.g., see the Climate Variability and Predictability (CLIVAR) science plan and objectives (www.clivar. org)]. Its monitoring has long been very difficult to

Corresponding author address: G. Reverdin, Laboratoire d'Océanographie et de Climatologie par Expérimentation et Analyse Numérique, Institut Pierre Simon Laplace, Université Pierre et Marie Curie, case 100, 4 pl. Jussieu, 75252 Paris CEDEX 05, France.

E-mail: gilles.reverdin@locean-ipsl.upmc.fr

DOI: 10.1175/JTECH2079.1

(C) 2007 American Meteorological Society achieve (Delcroix et al. 2005; Reverdin et al. 2007), and the accuracy with which this was done has long been rather low, both because of difficulties of gathering data with sufficient accuracy and because of insufficiencies in sampling (Bingham et al. 2002). The bulk of the data typically originated either from samples collected from a bucket [see Reverdin et al. (1994) for discussion of the accuracy of those data] or, since the early 1990s, from thermosalinographs placed on an interior circuit deriving the seawater from an intake placed at depths varying from less than $3 \mathrm{~m}$ to close to $15 \mathrm{~m}$ [see e.g., the Observatoire de Recherche en Environnement (ORE) 
SSS Web site (http://www.legos.obs-mip.fr/observations/ sss/) for typical installations on merchant vessels].

The situation has recently changed, in particular because of the advent of profiling floats equipped with salinity sensors (http://www.argo.ucsd.edu/). Although the float data can be of an accuracy better than 0.01 , in the real-time files from the floats, the accuracy is usually less. Furthermore, the floats were not initially designed to measure salinity very close to the surface, with the top measurement taken typically at $5 \mathrm{~m}$ from the sea surface. These data can nonetheless be used to ascertain the distribution of salinity stratification near the surface (Boutin and Martin 2006) and therefore estimate how representative the $5-\mathrm{m}$ data is of the near surface. The associated sampling is also limited to one occurrence typically every 10 days, with a recommended spatial distribution of floats of $3^{\circ}$ in longitude and the equivalent distance in latitude.

To make sure that surface salinity is appropriately monitored, satellite projects are being designed to measure ocean salinity from space [Soil Moisture and Ocean Salinity (SMOS) and Aquarius], the advantages being that coverage would be nearly global and that the parameter measured is related to near-surface salinity in the top $1 \mathrm{~cm}$ of the ocean. The difficulty is that this space-based measurement is rather inaccurate and will have to rely strongly on in situ data for its calibration. We would like here to discuss the accuracy of currently available in situ near-surface salinity data that can be collected for that calibration, based on the data collected during the COSMOS experiment that took place in 2005 in the Bay of Biscay. A variety of measurements was available in this area during COSMOS: data from thermosalinographs (TSGs) and water samples collected on various research and merchant ships, a rich dataset of CTD profiles, a few profiles from Argo-type profilers, and data from three types of surface drifters. We will not address here the issue of haline stratification near the surface that could cause differences between the 1-cm measurements and the in situ data [see Soloviev and Lukas (2006) for scientific discussions of near-surface haline stratification as a result of rainfall or evaporation].

The Bay of Biscay encompasses a deep-ocean area between France and Spain with spatial variability on the order of 0.1 pss-78 away from the shelves and the shelf breaks. Near the shelf breaks, there are larger gradients often associated with slope currents and shelf breaks (Pingree and Le Cann 1990; Serpette et al. 2006). There was little rainfall in 2005 and anomalously low river outflow, and this is not a region with large evaporation under low-wind conditions, so that we expect no large near-surface haline stratification most of the time. This is a region regularly sampled by research vessel TSGs, in particular during French and Spanish research cruises, and also crossed by merchant vessels equipped with TSGs. The near-surface circulation in this area away from the shelf break is rather weak and dominated by eddies (Pingree and LeCann 1990), so that drogued drifters released in this region do not wander very far.

\section{Data}

\section{a. Surface drifters}

The measurement of salinity from surface drifters has been attempted in the last $10 \mathrm{yr}$ with varying success. The first rather successful occurrence was during Coupled Ocean-Atmosphere Response Experiment (COARE) in the western Pacific Ocean [with Sea-Bird SeaCAT sensors placed at 11-m depth (Swenson et al. 1991)]. Estimated drifts in the measured salinities based on postrecovery calibration for four drifters having been up to 302 days at sea in the western tropical Pacific in 1994 did not exceed -0.02 pss-78 (A. L. Sybrandy 2006, personal communication). The Carioca drifter was then developed on another principle whereby salinity pumped from a 2-m depth is measured inside the buoy in a Sea-Bird MicroCAT cell slightly poisoned and flushed on an hourly basis (CopinMontégut et al. 2004). These drifters provided good results during the Programme Océan Multidisciplinaire Méso Echelle (POMME) 2001 experiment in the northeast Atlantic (Mémery et al. 2005), but they require a more complicated design than Surface Velocity Program (SVP) drifters. Their absolute accuracy is hard to ascertain, but current estimates based on recoveries or moored instrument comparisons indicate that they remain accurate to within 0.01 pss-78 for up to 6 months at sea.

Other drifters have been recently developed to measure temperature and salinity near the surface (typically in the top meter). During the COSMOS experiment in 2005 , three types of salinity drifters were deployed. Two of them, based on the SVP World Ocean Circulation Experiment (WOCE) principle, with a top sphere (41-cm diameter) attached to a drogue centered at a depth of $15 \mathrm{~m}$ (Niiler et al. 1995), will be respectively referred to as the Scripps Institution of Oceanography (SIO) and METOCEAN drifters (Fig. 1) and are designed for a life expectancy of up to $1 \mathrm{yr}$.

The SIO drifter uses an SBE 37-SI C-T system placed vertically along a cylindric hull attached to the surface sphere. Its conductivity cell extends over 14.5 $\mathrm{cm}$ with its intake/outlet at 35 and $49 \mathrm{~cm}$ (depth referred to the middle of the sphere, close to the expected 

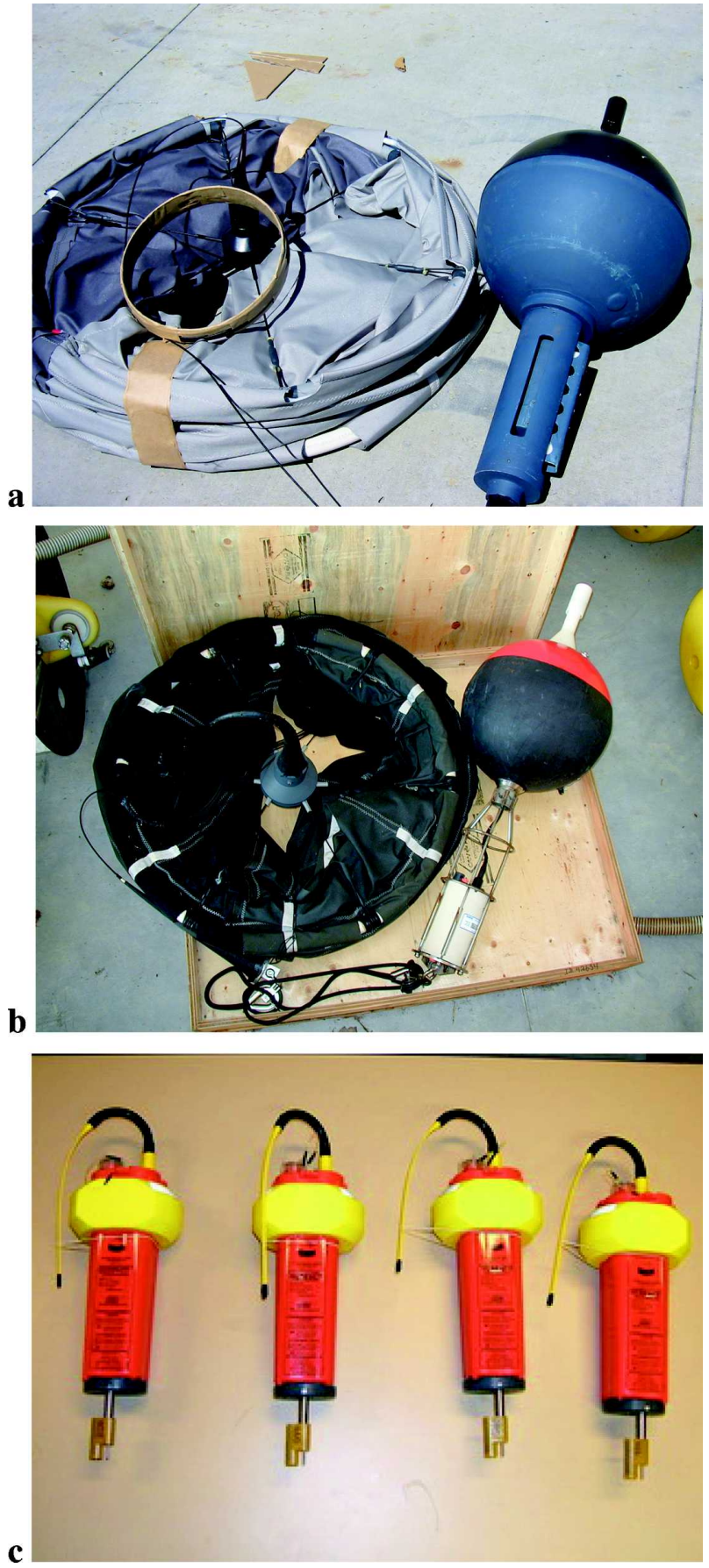

FIG. 1. The three salinity drifters used during the COSMOS experiment: (a) the SIO SVP model ( $\mathrm{C} / \mathrm{T}$ cell on the right side); (b) the METOCEAN SVP model (C/T cell underneath); (c) SURFACT drifters (C/T cell underneath).

flotation line), whereas the thermistor measuring temperature is located at $45-\mathrm{cm}$ depth.

The METOCEAN drifter uses an SBE 47 C-T system placed facing upward under the drifter top sphere (average depth of conductivity cell at $66 \mathrm{~cm}$ and of the thermistor at $56 \mathrm{~cm}$ ) and has, in addition, a hull thermistor placed roughly $15 \mathrm{~cm}$ below the surface (but with a lower resolution of $0.16^{\circ} \mathrm{C}$ ).

The third drifter, referred to as SURFACT, is a surface float with no drogue with a C-T ASD system and a life expectancy of 3 months. Earlier tests done with two SURFACTs from 26 February to 27 March 2004 off Banyuls-sur-Mer (http://www.obs-banyuls.fr/) indicated that the measurements were reliable but presented a bias $(-0.06$ and -0.20 pss- 78 , respectively). Part of the rms deviation with validation measurements (less than 0.05 pss-78) was related to often strong vertical stratification in the coastal environment (A. Lourenço et al. 2005, unpublished manuscript).

Salinity is estimated from the measured conductivity and temperature by the United Nations Educational, Scientific and Cultural Organization (UNESCO) recommended 1978 equation and is expressed as pss-78 (sometimes, this will be omitted). The reported salinity is an average of several individual estimates preceding the reported data time (10 over $10 \mathrm{~s}$ for SURFACT, 7 over $10 \mathrm{~s}$ for METOCEAN, and 5 over $5 \mathrm{~s}$ for SIO).

Seventeen surface drifters (12 SIO, 3 METOCEAN, 2 SURFACT) were deployed in the Bay of Biscay during two cruises in early April from R/V Thalassa and early May 2005 from R/V Cote de la Manche. Deployments were done by sets of at least three drifters (five such sets, three in early April and two in early May; Table 1), to provide intercomparison of data for the first weeks after deployment. The drifters usually kept their drogues during that period, and therefore drifter positions are usually close during at least two weeks after deployment. There are a few instances of longer proximity (group 5, e.g., for 50 days, and SIO 56368 and METOCEAN 42656 of group 4 for 70 days), or casual encounters later on that can also be used for intercomparisons.

The drifters provide series of $T$ and $S$ data (derived from the measured $T$ and conductivity) at hourly (METOCEAN) or half-hourly (SIO) intervals that are transmitted by Argos. The resolution of the reported data is $0.10(0.05){ }^{\circ} \mathrm{C}$ for temperature and $0.01(0.015)$ pss-78 for salinity (from SIO/METOCEAN drifters). This means that reported SSS can differ from measured SSS by up to 0.005 (0.0075) pss-78. When averaged over $3 \mathrm{~h}$, we expect that the average is closer to the measured values [to 0.003 (0.005) pss-78, respectively, for SIO (METOCEAN) drifters]. Few data are lost due to data transmission for METOCEAN, with more variable results for SIO drifters (the worst cases are SIO drifters 56364 and 56367, which were also poorly located). Of the data transmitted, always less than $10 \%$ was of du- 
TABLE 1. Dates of deployment of drifters during COSMOS 2005. The April deployments were done from the R/V Thalassa and the May deployments from the R/V Cote de la Manche.

\begin{tabular}{lccc}
\hline \hline Deployment/drifters & Launch date/time & Lat & Lon \\
\hline 1 & $2 \mathrm{Apr}$ & & \\
SIO-56362 & $2234 \mathrm{UTC}$ & $46.855^{\circ} \mathrm{N}$ & $5.902^{\circ} \mathrm{W}$ \\
SIO-56363 & & & \\
SIO-56373 & & & \\
2 & $3 \mathrm{Apr}$ & & \\
SIO-56365 & $0247 \mathrm{UTC}$ & $46.230^{\circ} \mathrm{N}$ & $6.495^{\circ} \mathrm{W}$ \\
SIO-56369 & & & \\
M-52198 & & & \\
3 & $3 \mathrm{Apr}$ & & \\
SIO-56366 & $0954 \mathrm{UTC}$ & $45.167^{\circ} \mathrm{N}$ & $7.488^{\circ} \mathrm{W}$ \\
SIO-56370 & & & \\
SIO-56371 & & & \\
4 & 1 May & & \\
SIO-56364 & $2300 \mathrm{UTC}$ & $45.794^{\circ} \mathrm{N}$ & $6.045^{\circ} \mathrm{W}$ \\
SIO-56368 & & & \\
M-42656 & & & \\
5 & 2 May & & \\
SIO-56367 & 0006 UTC & $45.600^{\circ} \mathrm{N}$ & $5.996^{\circ} \mathrm{W}$ \\
SIO-56372 & & & \\
M-52197 & & & \\
\hline
\end{tabular}

bious quality (except when drifters are stranded at the coast or in a near-shore environment). There is one 15-day-long instance of anomalously low SSS for drifter 56364 , which could have been related to an object stuck in the cell.

In three cases (SIO 56373, SURFACT 3376 and 3377), the drifter died suddenly at sea (after 3, 5, and 5 days, respectively). All the other drifters experienced the end of the spring bloom and at least part of the summer, as they were drifting over the deep part of the Bay of Biscay or its western approaches. The time series were often interrupted by grounding (four instances along the Asturian, Galician, Cantabrian, and the Landes coasts, respectively), recovery by fishing vessels close to shore (four instances between July and late October along the Asturian and Galician coasts of Spain), and recovery by research vessels (one in November and two in December). Altogether, eight drifters were brought back in 2005 and examined (one of which, S10 56365, was later redeployed in August), after a maximum stay at sea of 256 days. Six of the drifters stopped emitting at sea (including two of the three METOCEAN drifters, after 121 and 190 days, respectively) for unidentified reasons, but in some cases possibly because of low battery. The length of the longest time series of a recovered drifter is 600 days.

\section{b. Thermosalinograph data from vessels}

Salinity TSG data are available from the research vessels Thalassa, Beautemps Beaupré, and Cote de la
Manche, which had various cruises on the shelves and deep-ocean sector of the Bay of Biscay. In this area, there were also occasional TSG data from the research vessels Suroit and Belgica, as well as from some of the ships of opportunity managed by ORE SSS (C/S Rome, Pasteur, Nokwanda, Toucan, and Colibri). The TSGs on the research vessels get their water from an intake placed at a depth between 2 and $4.5 \mathrm{~m}$, whereas the range of intake depth on the ships of opportunity is much larger (between 3 and $>15 \mathrm{~m}$ ). Water samples are often available from research vessels, typically at a rate of once a day, in order to calibrate the TSG salinities. During some of the cruises (COSMOS-2 on R/V Cote de la Manche, cruises PELACUS, PELGAS, VACLAN, and EVHOE on the R/V Thalassa, and cruise MOUTON on the R/V Beautemps Beaupré), salinity values are available from CTD casts (often at a depth close to $3 \mathrm{~m}$ ), and samples collected from a bucket were also provided during two CONGAS cruises in early July and early December.

We estimate the CTD values to be accurate to within 0.01 pss-78 (often the real-time values were used, except for the COSMOS-2, MOUTON, and VACLAN cruises). Water samples were collected within doubleclosure bottles after triple-rinsing, as recommended for WOCE quality measurements, and the error related to the bottles and the later measurements on a salinometer is likely to be less than 0.003 pss-78. However, there are other sources of uncertainty for a comparison with TSG data. One is related to the reported time of sample collection, which easily results in an uncertainty in the comparison with the TSG SSS reaching 0.01 pss78 for an error in reported time of $5 \mathrm{~min}$. Another one occurs if the sample is collected by a bucket, and the bucket is not properly cleaned. This problem seems to have arisen at times during the first CONGAS cruise in early July 2005, resulting in excess salinity on the order of $0.02-0.03$ pss-78.

\section{c. Argo profilers}

Near-surface salinity data were also available from seven profiling floats of the Argo program (available online at http://www.coriolis.eu.org) in this region, with a large increase of the number of floats after the early July 2005 CONGAS cruise. The data are either from Apex floats at a depth close to $5 \mathrm{~m}$ deployed in July 2005 or from Provor floats averaged over the $0-10-\mathrm{m}$ depth interval and deployed in 2004 or 2005. The data we use are the uncorrected profiles.

\section{TSG salinity accuracy}

The TSG data accuracy is estimated from the comparison with the samples and with occasional CTD cast 
values. Often, the samples are taken as the ship is moving, whereas the casts correspond to situations with no motion. There is the possibility of data being less good en route, because of more bubbles being entrained through the conductivity cell. This seems to vary considerably from ship to ship. In that respect, the worst data en route are from the R/V Beautemps Beaupré, with frequent occurrences of noisy (too low) data (e.g., on 23 August, as evidenced by comparison with nearby drifters, or in early November, during a northeastward transect across the Bay of Biscay). This can be identified by large variations between successive measurements. This also happened during the first COSMOS-1 cruise on the R/V Cote de la Manche in early May for which the TSG was an ASD C/T system from the Laboratoire d'Océanographie et du Climat: Expérimentation et Approches Numériques (LOCEAN) with no bubble trap, in which bubbles accumulated regularly with occasional releases, resulting in sudden conductivity shifts with associated salinity changes larger than 0.1 pss-78.

Discarding these "noisy" data, the TSG salinity values drift mostly because of particles in the bath or deposits on the cell (fouling). In the worst cases, this can imply very large differences with the samples or the CTD values. This happened for the R/V Thalassa between 20 August and 2 September at 1200 UTC. (at which time, the cell was cleaned) (Fig. 1). In this case, the reported salinities are difficult to correct, as the comparisons suggest large changes within the same day, sometimes exceeding 0.2 (e.g., on 21 August 21, near 0900 UTC). Some of the changes are associated with sudden jumps of the conductivity, but at other times the changes seem more gradual (22 August to 1 September). For the particular case of the R/V Thalassa shown in Fig. 2, we have a large number of comparisons with CTD casts data that allow us to identify when changes occur.

On the other hand, at other times, and in particular when only one sample is collected each day, there is the possibility that we have missed some of the changes in bias, so that the accuracy of the "corrected" data file is difficult to ascertain. For example, in late April/early May, the large differences between the comparison with the CTD data and the one with the sample data in Fig. 2 suggest that accuracy in corrected TSG salinity is no better than 0.05 pss- 78 . There are also long periods during which the bias of the cell seems to have remained rather constant, in particular in cases when the biases identified by the comparisons with samples or CTD values are on the order of -0.1 pss- 78 or less (e.g., for the Thalassa in April/early May, or from 6 to 15
September; Fig. 2). In those cases, corrections should result in accuracies better than 0.01 pss-78 in the corrected SSS data (uncertainties are estimated from the statistics over five successive points of comparison, which can be distributed over more than 5 days). Another such example is found for the $\mathrm{R} / \mathrm{V}$ Suroit on 2 April, with a bias of $-0.117 \pm 0.005$ identified based on the comparison with the data of the R/V Thalassa on the same track across the Bay of Biscay the day before and with the drifters that had just been deployed. There are also instances when no significant bias can be detected (instrument cleaned recently or no fouling), as was found for the R/V Thalassa on 1-2 April (Fig. 2) or for the R/V Cote de la Manche on 22-23 June. In those instances, the TSG salinity is probably accurate to within 0.003 pss-78.

\section{Drifter salinity biases}

\section{a. Drifter salinity diurnal peaks}

The salinity time series (Fig. 3) present usually a slow evolution, except for isolated bad data and periods of a few hours of outliers, mostly with higher salinities for the SIO drifters and lower salinity for the METOCEAN drifters. They appear mostly during daytime hours on a limited number of days. For the METOCEAN drifters, which have a temperature measured at $15 \mathrm{~cm}$ from the surface, these days all have a daily warming of at least $1{ }^{\circ} \mathrm{C}$, which occurs during 45 drifter days. A majority of these occurrences correspond to weak winds, according to collocated 6-hourly winds from the Action de Recherche Petite Echelle Grande Echelle (ARPEGE) operational model of Météo-France (less than $3 \mathrm{~m} \mathrm{~s}^{-1}$ during part of the day in 38 out of 45 cases, and more than half with the model winds less than $2 \mathrm{~m} \mathrm{~s}^{-1}$ ).

We will illustrate two situations that are fairly typical with two drifters, SIO-56368 and METOCEAN-42656, which drifted in the same area. The first one (Fig. 4) is for 1-2 June. Both days have large daily cycles with a more regular cycle during 1 June than 2 June. During 1 June, the temperature daily cycle is fairly similar for the two temperature sensors of M-42656 (at 15 and $56 \mathrm{~cm}$ ) and the temperature sensor of SIO-56368 (at $45 \mathrm{~cm}$ ). The daily peak deviations of salinity are for both drifters on the order of 0.04-0.05 pss-78. If there was no real daily cycle of salinity, this would imply that the temperatures experienced in the conductivity cell would be on the order of $0.05^{\circ} \mathrm{C}$ lower than the one measured for SIO-56368 and $0.05^{\circ} \mathrm{C}$ higher than the one measured for M-42656. There seems to be little vertical gradient from 15- to 56-cm depth, but this does not rule out gradients below $56 \mathrm{~cm}$ on the order of $0.05^{\circ} \mathrm{C}$ over the 
a

SSS TSG bias (CTD or sample)

R/V Thalassa 2005

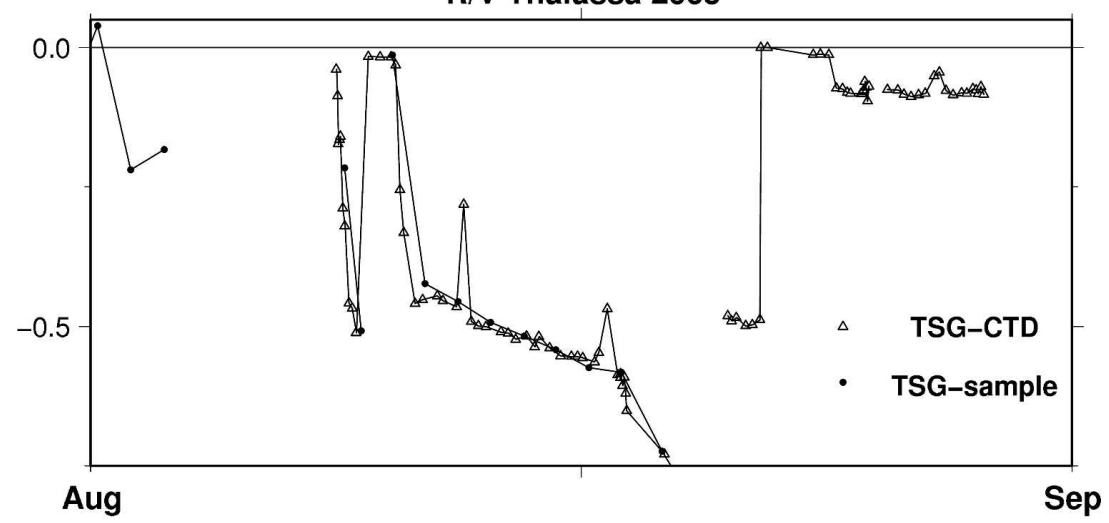

b

SSS TSG bias (CTD or sample)

R/V Thalassa 2005

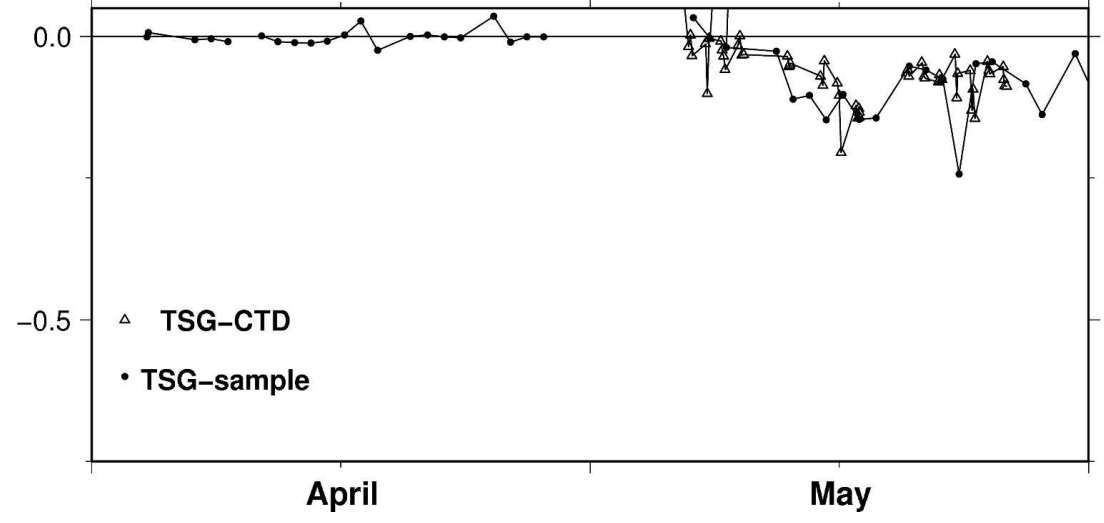

FIG. 2. Comparison of the TSG salinity of the R/V Thalassa with CTD 3-m values (triangles) and water samples collected at the TSG (dots) for two periods [(a) mid-August to mid-September; (b) April and May].

near $10 \mathrm{~cm}$ between the level of the thermistor and the conductivity cell.

During 2 June, the amplitude of the daily cycle is larger (exceeding $1.5^{\circ} \mathrm{C}$ at $15 \mathrm{~cm}$ ), and there is a large temperature gradient until 1800 UTC between 15- and 46-cm depth for drifter M-42656. This is during this period that the negative peak of salinity occurs and in particular near the end, when it exceeds 0.12 pss-78 at 4:55 and 5:55 P.M. Assuming that this peak is artificial would imply that the temperature measured by the thermistor is up to $0.13^{\circ} \mathrm{C}$ higher than the temperature witnessed in the cell at $56-\mathrm{cm}$ depth. This gradient of $0.013^{\circ} \mathrm{C} \mathrm{m}^{-1}$ is certainly compatible with a background temperature stratification, especially at the end of the afternoon, when the heating penetrates deeper. The positive salinity deviation for SIO-56368 is also during this daytime period and peaks at 0.6 pss-78 at 1608 UTC (and 0.42 pss-78 at 1538 UTC). It decreases to 0 pss-78 at 5:38 P.M. This would imply a peak temperature difference of $0.65^{\circ} \mathrm{C}$ between the thermistance at $45 \mathrm{~cm}$ and the conductivity cell. This is not incompatible with the difference between the relatively low $T$ at $45 \mathrm{~cm}$ and the relatively high $T$ at $15 \mathrm{~cm}$ of M-42656 found near 3:30-4:00 P.M. The secondary increase of temperature during the early night for M-42656 and not for SIO-56368, however, is a warning that the daily temperature cycle can be quite different between two drifters separated by just $7 \mathrm{~km}$ (a similarly large difference is also found on 26 May, another day with large daily cycles and drifters also within $7 \mathrm{~km}$ of each other).

Whereas in the previous examples the peak deviations are in the afternoon, on 23 June (Fig. 5), with the two drifters separated by nearly $13 \mathrm{~km}$, they happen in the late morning. Indeed, there is little difference be- 


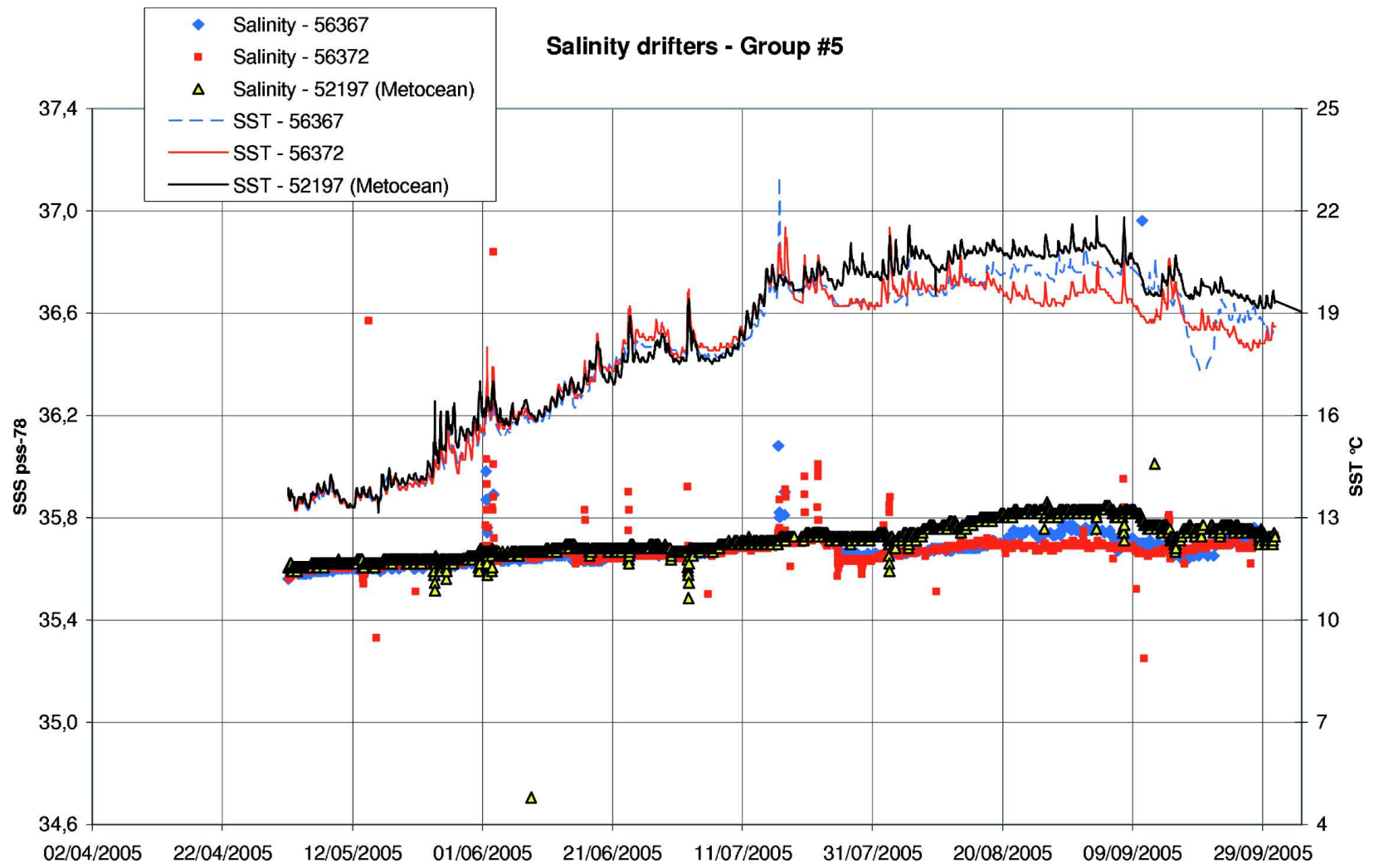

FIG. 3. Salinity and temperature records of three drifters of deployment 5 (Table 1) until the end of September 2005. The drifters remained relatively close together in May.

tween the two temperature sensors of M-42656 (at 15 and $56 \mathrm{~cm})$ at 1355 UTC, which could result from slightly larger winds in the early afternoon, as suggested by the ARPEGE winds. Maximum $T$ at $15 \mathrm{~cm}$ was observed at 1156 UTC (the 1355 UTC measurements are missing), and a maximum positive salinity deviation for SIO-56368 of 0.2 pss-78 is at 1130 UTC. These deviations would imply a temperature in the conductivity cell higher by $0.45^{\circ} \mathrm{C}$ compared to the measured one. This is not incompatible with the huge temperature gradient $\left(>2^{\circ} \mathrm{C}\right)$ between 15 and $56 \mathrm{~cm}$ on M-42656 at 1155 UTC. For M-42656, the salinity differences are more modest, reaching 0.045 pss-78, and therefore suggest a temperature difference of $0.05^{\circ} \mathrm{C}$ between the $56-\mathrm{cm}$ thermistor and the $66-\mathrm{cm}$ cell depth. Further tests in summer 2006 from a SURFACT drifter attached to a METOCEAN drifter indicate, during days of large surface warming, anomalously low METOCEAN salinity compared to the SURFACT salinity.

These examples illustrate that it is highly likely that the large salinity changes during large midday warming are a result mostly of mismatches between the thermistor and the conductivity cell depths. During the May to September period (roughly 150 days), we find on the order of 15 days with large temperature cycles. Not all of those present large deviations of salinity, with only a few exceeding the 0.1 pss-78 range (slightly less for METOCEAN than SIO drifters). When combined and averaged over the time series, they result in an $O(0.01$ pss-78) daily cycle, and a bias less than 0.005 pss-78 for the average salinity from the drifter. However, we do not know whether on other days there is a small residual bias in daytime salinity (probably less than 0.01 pss-78, as it does not show up significantly when estimating an average daily cycle from these data). In the later comparisons, we chose to exclude data from 0900 UTC to 1800 UTC.

\section{b. Estimates of drifter biases}

To estimate drifter salinity biases, we use comparisons at deployment, during the drifter life at sea, and at recovery or during postrecovery calibrations.

Except for the three METOCEAN drifters, no recent bath comparisons of the drifter salinities were available before deployment. To validate the initial bias, we rely on both comparison of the drifter salinity with a sample collected at deployment and intercomparison of salinity from two close-by drifters. We found 


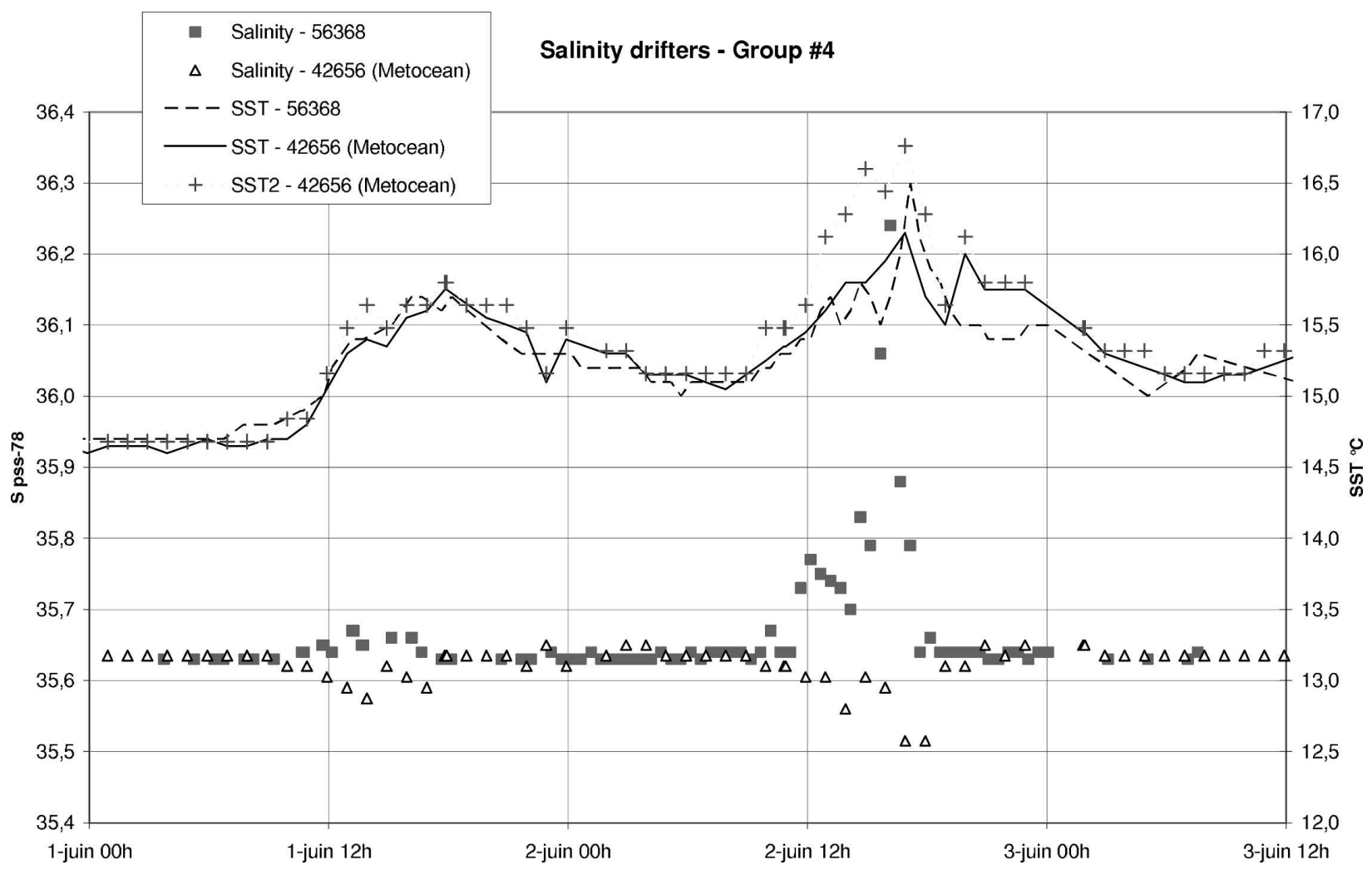

FIG. 4. Temperature and salinity from two close-by drifters $(7 \mathrm{~km})$ on 1 and 2 Jun (SIO-56368 and M-42656). The two temperature records of M-42656 (SST2 is the upper one at 15-cm depth with a dotted line).

that METOCEAN drifter salinities were stable by the first data transmitted within an hour of deployment, whereas salinities from the SBE 37-SI sensor on the SIO drifters took longer to adjust for 7 of 12 drifters, with the first value off for those drifters by more than 0.05 from the equilibrated value 3-6 h later. In one extreme case, SIO-56364, the initial value was off by 0.38 . We do not expect salinity to vary much over that time (no rain was recorded after the deployments), and this initial adjustment is of no interest for the later behavior of the bias. For the SIO drifters, what we call an initial bias will be the bias obtained by assuming that the drifter SSS after the initial setup period is equal to the initial one. In six instances when a METOCEAN drifter is nearby, we preferred to compare the SSS of the SIO and METOCEAN drifters after the initial SSS drift period. To this difference, we add the estimated METOCEAN initial SSS bias to estimate the SIO initial bias, which can differ by more than 0.01 pss- 78 from the other estimation of its initial bias.

Altogether, and taking into account the data resolution, we expect that we can estimate the initial bias to within 0.010 pss-78 in the worst instance and to within 0.005 pss-78 in the best case. The estimated biases for
METOCEAN drifters range from -0.006 to 0.008 pss78 (average $-0.001 \mathrm{pss}$ ), whereas the estimated biases for SIO drifters range from -0.026 to +0.009 pss- 78 (average -0.015 pss-78). This average is very significantly nonzero (one standard deviation of the error on the estimate less than 0.002), possibly the result of the environment influencing the conductivity in the cell. The average biases for the two SURFACT drifters were also negative ( -0.001 and -0.011 pss-78, respectively).

The best comparisons when the drifters were at sea were provided during the COSMOS-2 cruise in late June, when 12 of the 14 drifters still emitting were visited. The comparisons were both with a water sample, the Cote de la Manche TSG records, and a CTD cast done nearby, with very close agreement between the different values. The comparison of the salinities suggested a slight increase in the drifter SSS negative bias (averaged increase of -0.007 pss-78, with individual increases between +0.002 and -0.018 pss-78). These averaged comparisons are likely to have a standard deviation error of 0.003 (0.005) pss-78 for SIO (METOCEAN) drifters. The increase suggests some aging of the cells or moderate fouling (average time since deployment of 65 days). 


\section{Salinity drifters - Group \#4}

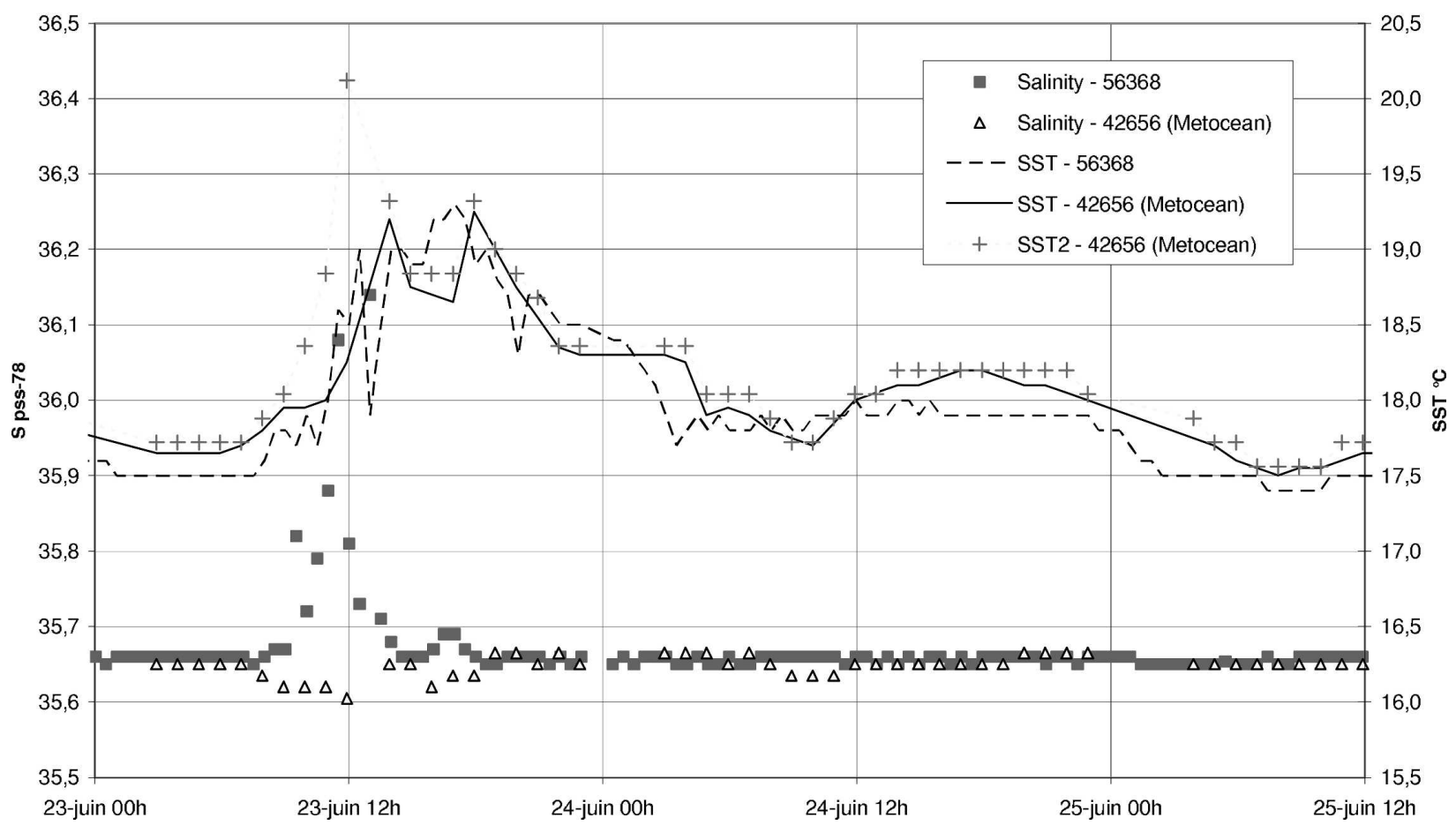

FIG. 5. Temperature and salinity from two close-by drifters $(7 \mathrm{~km})$ on 23 and 24 Jun (SIO-56368 and M-42656). The two temperature records of M-42656 (SST2 is the upper one at 15-cm depth with a dotted line).

Other comparisons are provided by chance encounters with research vessels (Cote de la Manche, Thalassa, and Beautemps Beaupré) or with other drifters. These comparisons, summarized in Table 2, are often less reliable. They consist of three close encounters with a research vessel (end of August or early September), that indicate a larger bias than during COSMOS-2 at the end of June, by $-0.001,-0.010$, and -0.017 pss-78, respectively. The other three encounters with a research vessel in the same late summer season are much less reliable, but two out of three also indicate an increase. The average of these six comparisons indicates an increase of -0.006 pss-78 in 70 days (standard error of 0.004 pss-78) (if only retaining the three more certain ones, average of -0.009 pss-78 with standard error of 0.003 pss-78). When redeploying on 28 August, drifter SIO-56365, recovered a month earlier in July, we found a very large initial bias of -0.090 (but could be -0.060 if based on data a few hours later). This could imply that the bias increased by -0.032 to -0.062 during the month between 25 June 25 and 23 July, when the drifter was brought ashore, but it is likely that the bias increased further after recovery during baths in laboratory tanks done in an attempt to estimate the bias. Finally, drifter SIO-56362 had close encounters with drifters SIO-56370 and SIO-56371, suggesting that its bias was probably -0.030 by 10 August, an increase of -0.022 with respect to the comparison on 25 June, 46 days before. These comparisons suggest a wide range of increase in bias during the summer period. On individual drifters, no link is found between the increases in bias during spring and summer.

Finally, there are in situ data collected during recovery on 7 December for two drifters (SIO-56368 and M-52197) and during later bath measurements done in late December and January for the seven drifters brought ashore after the cell was rinsed with freshwater. All drifters recovered in the autumn were widely covered with shellfish and algae (Fig. 6), although it is not clear whether there was special fouling associated with that in the conductivity cell. Actually, one of the seven drifters (SIO-56368) indicates no increase in bias since the end of June or deployment, whereas three indicate very moderate increases in bias since COSMOS- 2 at the end of June ( -0.010 pss- 78 or less). The three others, on the other hand, indicate a large increase in bias by more than -0.030 pss- 78 since the end of August (one of which, SIO-56363, was recovered by a fisherman on 29 September, and the two others in November and December). Except for the two that had 
TABLE 2. Estimated salinity biases (pss-78) by comparison with in situ data at launch, during the COSMOS-2 cruise and later encounters with research vessels [(c) indicates close encounter with $R / V$; (f) is far encounter with $R / V$; and (d) is deployment from R/V for SIO-56365]. Estimates based on the intercomparison of nearby drifters are also indicated, as well as date of recovery (and estimated bias when available), and postrecovery estimates.

\begin{tabular}{|c|c|c|c|c|c|c|}
\hline Drifter & $\begin{array}{l}\text { Launch } \\
\text { date/bias }\end{array}$ & $\begin{array}{l}\text { COSMOS-2 } \\
\text { (22-28 Jun) }\end{array}$ & $\begin{array}{l}\text { R/V TSGs } \\
\text { date/bias }\end{array}$ & $\begin{array}{l}\text { Other drifters } \\
\text { date/bias }\end{array}$ & $\begin{array}{c}\text { Recovery/loss } \\
\text { date bias }\end{array}$ & Postrecovery bias \\
\hline SIO-56362 & 2 Apr/- 0.010 & -0.008 & $7 \mathrm{Sep} /-0.030$ (f) & 7-13 Aug/-0.030 & $3 \mathrm{Dec}$ & 28 Jan $2006 /-0.066$ \\
\hline SIO-56363 & 2 Apr/-0.012 & -0.029 & 31 Aug/-0.030 (c) & & 29 Sep & 28 Jan $2006 /-0.061$ \\
\hline SIO-56364 & $1 \mathrm{May} /-0.026$ & & & & 11 Mar 2006 (grounded) & \\
\hline SIO-56365 & $2 \mathrm{Apr} /-0.020$ & -0.0028 & $28 \mathrm{Aug} /-0.090$ (d) & & 3 Oct (loss) & \\
\hline SIO-56366 & $2 \mathrm{Apr} /-0.015$ & -0.016 & & & 19 Aug (grounded) & \\
\hline SIO-56367 & $1 \mathrm{May} /-0.017$ & -0.027 & $6 \mathrm{Sep} /-0.040$ (f) & $12 \mathrm{Dec} /-0.020$ & 21 Dec 2006 & \\
\hline SIO-56368 & $1 \mathrm{May} / 0.009$ & -0.009 & & & 7 Dec/-0.005 & 2-4 Feb 2006/-0.011 \\
\hline SIO-56369 & $2 \mathrm{Apr} /-0.020$ & -0.031 & & & 17 Sep (grounded) & \\
\hline SIO-56370 & $2 \mathrm{Apr} /-0.019$ & -0.028 & 4 Sep/-0.010 (f) & 7 Aug/-0.030 & $23 \mathrm{Sep}$ & 5-7 Dec/-0.034 \\
\hline SIO-56371 & $2 \mathrm{Apr} /-0.019$ & -0.020 & & 13 Aug/-0.025 & $5 \mathrm{Nov}$ & 5-7 Dec/-0.028 \\
\hline SIO-56372 & $1 \mathrm{May} /-0.007$ & -0.015 & $8 \mathrm{Sep} /-0.025$ (c) & & 16 Nov & 5-7 Dec/-0.051 \\
\hline SIO-56373 & $2 \mathrm{Apr} /-0.012$ & & & & 8 Apr (loss) & \\
\hline M-42656 & $1 \mathrm{May} /-0.006$ & -0.017 & $30 \mathrm{Aug} /-0.034$ (c) & & 30 Sep & \\
\hline M-52197 & 1 May/0.008 & 0.001 & & & $8 \mathrm{Dec} /-0.010$ & 2-4 Feb 2006/-0.009 \\
\hline M-52198 & $2 \mathrm{Apr} /-0.005$ & & & & 31 July & \\
\hline S-3376 & $2 \mathrm{Apr} /-0.002$ & & & & 7 Apr (loss) & \\
\hline S-3377 & $2 \mathrm{Apr} /-0.011$ & & & & 7 Apr (loss) & \\
\hline
\end{tabular}

both a comparison at recovery and a later bath comparison, we cannot be sure that the bath comparison will be indicative of the bias at sea. Nonetheless, this leaves the possibility that a bias increase as large as -0.030 pss-78 could have happened in a month's time (drifter SIO-56363).

This contrasts with the situation for SIO-56367, which drifted to within $1 \mathrm{~km}$ of the CARIOCA moor- ing "Minas" (near $43^{\circ} \mathrm{N}, 11^{\circ} \mathrm{W}$ on the north slope of the Galicia bank) on 12 December. The simultaneous data suggest that the drifter bias was not larger than -0.020 pss-78. This implies a decrease of the bias since the previous comparisons during the summer. We find, therefore, that the autumn is a season if strong contrast in terms of bias evolution, with some increases and some decreases found in biases.

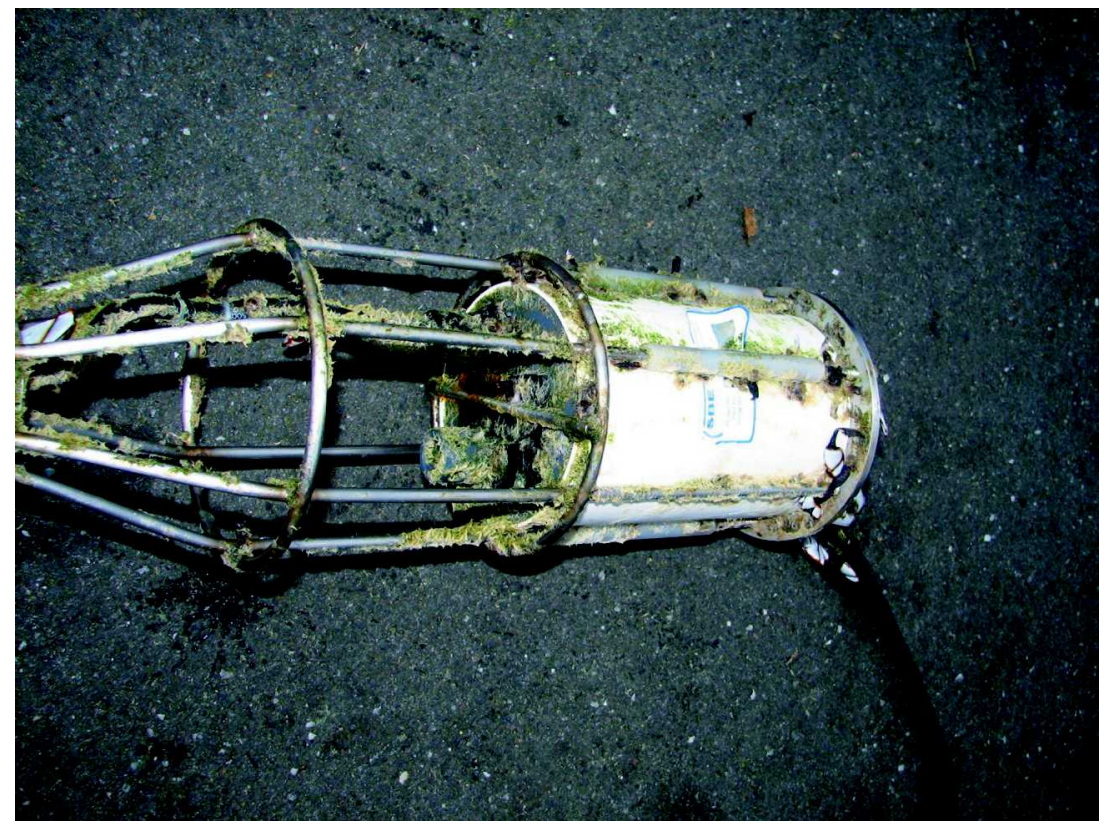

FIG. 6. The sensors of M-52197 shortly after recovery. 


\section{c. Comparison with ocean color data}

To evaluate fouling conditions, we considered ocean color, an indicator of chlorophyll and phytoplankton biomass in the surface water. For that, we collocate drifter locations with chlorophyll content derived from MERIS and MODIS satellite data. These maps are built by the CoastWatch project (www.enviport.org/ coastwatch) at $0.01^{\circ}$ resolution using a combination of data acquired during the past 7 days, with a priority given to the most recent data; they are updated every day. Then, for each buoy, we compute a "mean" collocated chlorophyll during a given period derived from collocated chlorophyll linearly interpolated in time (in order to fill gaps due to clouds). Figure 7 shows SSS drifts versus mean chlorophyll computed between deployment and 25 June (COSMOS-2 cruise), and between 25 June and research vessel TSG calibration in summer (see Table 2). The spring bloom lasted through April and May, with some areas retaining a high chlorophyll content until late June or even later. These average chlorophyll contents near $0.8 \mathrm{mg} \mathrm{m}^{-3}$ (for an average 65-day period) are characteristic of productive oligotrophic waters. Because the drifters have crossed large areas and do not always stay in particularly rich patches, the average spring chlorophyll is actually fairly similar for all the drifters, despite large differences in bias change (Fig. 7). So, we do not find a larger bias for drifters having experienced higher maximum chlorophyll content. Chlorophyll was much lower in summer than in spring, but we did not find less change in bias during the summer season (the drifter with a large positive SSS bias change corresponds, in fact, to a case of less certain comparison in Table 2). This suggests that the fouling of the cells cannot be estimated just as a function of past "ocean color."

\section{Conclusions}

COSMOS provided an opportunity to estimate the feasibility of obtaining near-surface salinities from a variety of different instruments. It took place in the Bay of Biscay, mostly away from the shelves, in a region that can experience fairly large daily warming from April to September. In this area, which does not experience very large evaporation or rainfall, we expect that the nearsurface haline stratification between $10 \mathrm{~cm}$ and $5 \mathrm{~m}$ is small $[O(0.01)]$ most of the time. We found instances on 20-22 April, when drifter salinity drops were related to rainfall events, but this was an uncommon situation, and usually data from different depths in this depth range can be considered as representative of the same quantity.
Chl versus SSS bias

Bias between deployment and 22-28/06

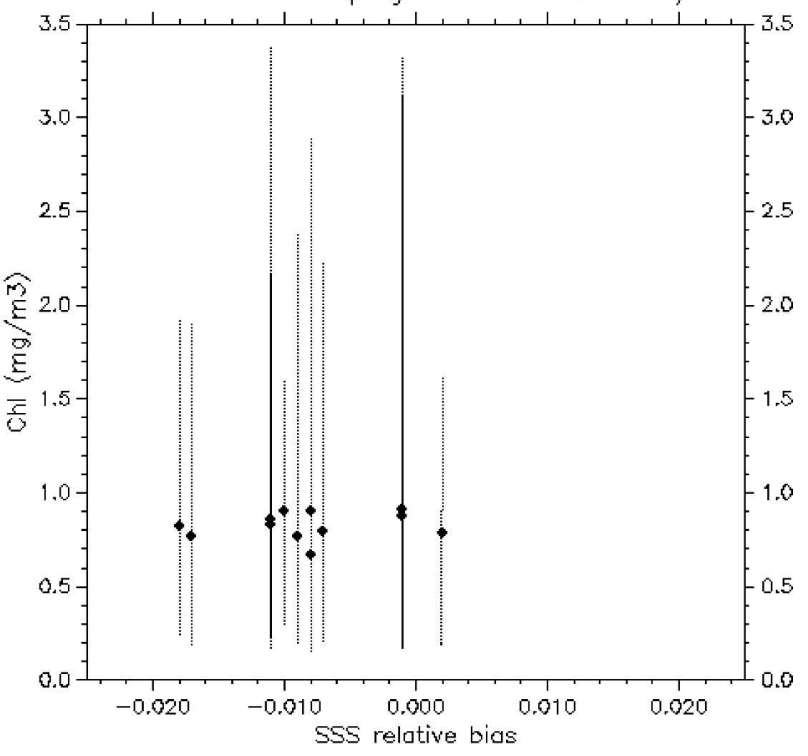

Chl versus SSS bias

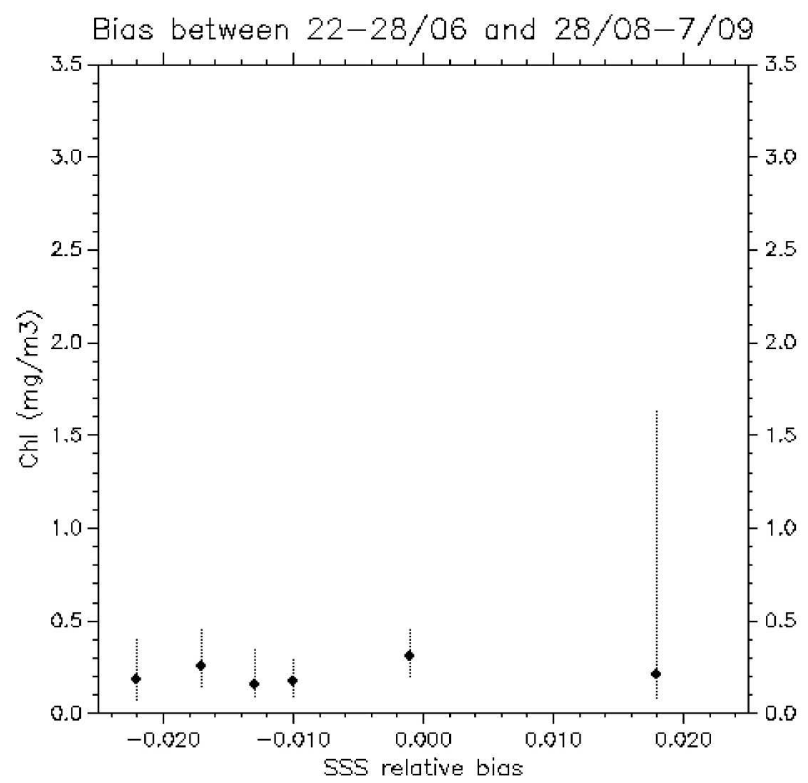

FIG. 7. Change in SSS bias (horizontal axis) and chlorophyll-A (vertical axis) during given periods: (top) launch date to $25 \mathrm{Jun}$; (bottom) 25 Jun to research vessel TSG calibration in summer [the point with large positive bias change corresponds to drifter 56370 and is based on an (f) comparison (Table 2), and could as well have had a null bias change]. Average chlorophyll is indicated, with bars connecting the lowest and highest values of collocated chlorophyll.

We first illustrated that data from thermosalinographs on board research vessels were difficult to validate and that a large set of validation data (from water samples and CTD casts) is necessary to correct the sa- 
linity biases. We also were able to compare and validate salinity data from 17 drifters, mostly from two types of SVP drifters with unpumped C/T cells. To our surprise, the biases experienced fairly similar increases during spring and summer $(-0.007$ and -0.006 pss-78, respectively), although there was some scatter in this evolution between the different drifters.

The spring bloom in these regions has often a large contribution of diatom cells, quite probably of medium to large size (microplankton), leading usually to nutrient depletion during early summer. We expect phytoplankton to have smaller cells in summer and to be associated with a regenerated activity through the bacterial loop and grazing. The organisms or biochemicals contributing to cell fouling should therefore be different during the two seasons. Why salinity drifts of the cells are fairly similar in the two seasons remains to be explained. We also found quite a large scatter in the evolution of bias during the autumn, with even smaller biases (less negative) in some instances. Without other in situ data, the drifter salinity data would be hard to correct to the hoped-for $0.01-0.02$ pss-78 accuracy that one can attain, for example, from validated Argo data.

We also pointed out occasional errors in estimating daytime salinity in the presence of large near-surface temperature stratification that are related to the cell design. These erroneous estimates that occur during $2 \%$ of the time during the whole dataset can easily be identified and removed. To properly assess daily cycles of salinity with drifters, it will be necessary to modify the instrumental design so that the temperature measured represents more closely the temperature in the conductivity cell.

The results are nonetheless very encouraging for the use of these drifters in such midlatitude environments. How they behave in other environments, in particular in warmer tropical waters or in situations of massive blooms of the North Atlantic subpolar region, for example, remains to be investigated. Further tests remain to be done on the SURFACT drifters. It is, however, already clear from tests in 2006 that their measurements are more sensitive to fouling. They might, on the other hand, provide a more accurate estimate of daily salinity changes relatively close to the sea surface (20 $\mathrm{cm})$. The relative advantage of these simple cell systems with respect to more sophisticated pumped cell $\mathrm{C} / \mathrm{T}$ measurements also remains to be evaluated.

Acknowledgments. In addition to the authors, Nicolas Martin contributed to the data processing, and Thierry Monglon and Stephanie Contardo to the deployment of drifters and to the survey during the
COSMOS-2 cruise in late June 2005. We are also particularly grateful to the help provided by the crews of the R/V Thalassa and Cote de la Manche for the deployment and tracking of the drifters. The recoveries of the drifters at sea were done by the R/V Nereis (Roscoff, France) and during the CONGAS-2 cruise (thanks to Alain Serpette and SHOM), as well as by various fishermen and personnel of the IEO institutes in Gijon and Santander and IIM in Vigo, and the tourist office of Courtis-Plage (Landes), to which we are very indebted, with special thanks to Alicia Lavin (IEO). Funding for the research was provided by CNES, and the efforts to collect water samples and real-time TSG data from French research vessels is done by CORIOLIS.

\section{REFERENCES}

Bingham, F. M., S. D. Howden, and C. J. Koblinsky, 2002: Sea surface salinity measurements in the historical database. J. Geophys. Res., 107, 8019, doi:10.1029/2000JC000767.

Boutin, J., and N. Martin, 2006: ARGO upper salinity measurements: Perspectives for L-band radiometers calibration and retrieved sea surface salinity validation. IEEE Geosci. Remote Sens. Lett., 3, 202-206.

Copin-Montégut, C., M. Bégovic, and L. Merlivat, 2004: Variability of the partial pressure of $\mathrm{CO} 2$ on diel to annual time scales in the northwestern Mediterranean Sea. Mar. Chem., 85, 169189.

Delcroix, T., A. Dessier, Y. Gouriou, and M. McPhaden, 2005: Time and space scales for sea surface salinity in the tropical oceans. Deep-Sea Res. I, 52, 787-813.

Mémery, L., G. Reverdin, J. Paillet, and A. Oschlies, 2005: Introduction to the POMME special section: Thermocline ventilation and biogeochemical tracer distribution in the northeast Atlantic Ocean and impact of mesoscale dynamics. J. Geophys. Res., 110, C07S01, doi:10.1029/2005JC002976.

Niiler, P. P., A. L. Sybrandy, K. Bi, P. Poulain, and D. Bitterman, 1995: Measurements of the water-following capability of holey-sock and TRISTAR drifters. Deep-Sea Res. I, 42, 19511964.

Pingree, R. D., and B. Le Cann, 1990: Structure, strength and seasonality of the slope currents in the Bay of Biscay region. J. Mar. Biol. Assoc. UK, 70, 857-885.

Reverdin, G., D. Cayan, H. D. Dooley, D. J. Ellett, S. Levitus, Y. du Penhoat, and A. Dessier, 1994: Surface salinity in the North Atlantic: Can we reconstruct its fluctuations over the last one hundred years? Prog. Oceanogr., 33, 303-346.

_ , E. Kestenare, C. Frankignoul, and T. Delcroix, 2007: Surface salinity in the Atlantic Ocean $\left(30^{\circ} \mathrm{S}-50^{\circ} \mathrm{N}\right)$. Prog. Oceanogr., 73, 311-340.

Serpette, A., B. Le Cann, and F. Colas, 2006: Lagrangian circulation of the North Atlantic central water over the abyssal plain and continental slopes of the Bay of Biscay: Description of selected mesoscale features. Sci. Mar., 70SI, 27-42.

Soloviev, A., and R. Lukas, 2006: The Near-Surface Layer of the Ocean: Structure, Dynamics and Applications. Springer, $572 \mathrm{pp}$

Swenson, M. S., and Coauthors, 1991: Feasibility of attaching SEACATs to TOGA drifters. SIO Rep. 91-30, 39 pp. 